\title{
A case of distal extrahepatic cholangiocarcinoma with two positive resection margins
}

\author{
WAYNE A. WARNER ${ }^{1}$, WESLEY RAMCHARAN ${ }^{2}$, DAVE HARNANAN $^{2}$, \\ SRIKANTH UMAKANTHAN ${ }^{2}$ and RAVI MAHARAJ ${ }^{2}$
}

\author{
${ }^{1}$ Division of Oncology, Siteman Cancer Center, Department of Cell Biology and Physiology, \\ Washington University School of Medicine, St. Louis, MO 63110, USA; ${ }^{2}$ Department of Clinical Surgical Sciences, \\ University of The West Indies, Eric Williams Medical Sciences Complex, Champ Fleurs, Trinidad and Tobago
}

Received June 1, 2016; Accepted August 25, 2016

DOI: $10.3892 / 01.2016 .5174$

\begin{abstract}
Cholangiocarcinoma is an uncommon primary malignancy of the biliary tract that is challenging to diagnose and treat effectively due to its relatively silent and late clinical presentation. The present study reports a case of a 60-year-old male with distal extrahepatic cholangiocarcinoma with a 3 -week history of painless obstructive jaundice symptoms and subjective weight loss. Imaging revealed an obstructing lesion in the common bile duct, just distal to the entrance of the cystic duct. Pathology revealed moderately differentiated cholangiocarcinoma with two positive proximal resection margins. The two positive resection margins presented a challenge during surgery and points to an urgent need for further studies to better illuminate diagnostic and therapeutic options for patients with similar clinicopathological presentation.
\end{abstract}

\section{Introduction}

Cholangiocarcinoma (CCA), an extremely rare and highly aggressive malignant tumor was first described in 1957 (1). They are cancers of the epithelial cells in the extrahepatic or intrahepatic biliary tree of the bile duct from the bile ductules to the Ampulla of Vatar (2-4). CCA is often diagnosed in patients $>60$ years and the prognosis is poor in the majority of cases $(5,6)$. Furthermore, CCA is often difficult to diagnose and treat due to its growth pattern, silent nature (wherein its symptoms go unnoticed by the patient until the advanced stage), anatomical location, non-specific clinical presentation and limited clinical approaches. CCA is the second most common primary hepatic tumor globally, accounting for $3 \%$ of

Correspondence to: Dr Wesley Ramcharan, Department of Clinical Surgical Sciences, University of The West Indies, Eric Williams Medical Sciences Complex, Uriah Butler Highway, Champ Fleurs, Trinidad and Tobago

E-mail: wtramcharan@hotmail.com

Key words: distal extrahepatic cholangiocarcinoma, pancreaticoduodenectomy, two positive proximal resection margins all gastrointestinal tumors, though that rate is increasing $(7,8)$. Worldwide, the highest CCA rates have been reported in Eastern Asia, particularly Thailand, where its high incidence is attributable to liver fluke infection (9). To the best of our knowledge, case reports of distal extrahepatic CCA with two positive resection margins are rare. This is the first reported CCA case from the Caribbean (30 island nations, population, 39.8 million) and more specifically, Trinidad and Tobago (population, 1.3 million).

\section{Case report}

The present study presents a case of a distal extrahepatic cholangiocarcinoma with its imaging and clinicopathological details, as well as the epidemiology of CCA in Trinidad and Tobago. A 60-year-old male non-smoker of African and Indian ethnicity, with no previously known medical conditions presented to the Eric Williams Medical Sciences Complex, Champ Fleurs (Trinidad and Tobago) with a 3-week history of painless obstructive jaundice symptoms and subjective weight loss. The patient has a family history of breast, prostate and lung cancer (Fig. 1). The patient's mother and an aunt succumbed to lung and breast cancer, respectively; the patient's father has prostate cancer and several of his uncles have prostate and/or colon cancer.

On examination, the patient had icterus and a palpable gallbladder. Complete blood count, renal function and international normalized ratio tests were normal, but his liver function tests were abnormal: Total bilirubin, $9.1 \mathrm{mg} / \mathrm{dl}$ and bilirubin, $4.5 \mathrm{mg} / \mathrm{dl}$. Computed tomography (CT) of the chest, abdomen and pelvis scan revealed dilated intra-hepatic ducts, gallbladder, cystic duct and common hepatic duct, just distal to entrance of cystic duct (Fig. 2). Magnetic resonance cholangiopancreatography (MRCP) revealed an obstructing lesion in the common bile duct with proximal extent just distal to the cystic duct and distal extent just superior to the upper border of the pancreas (Fig. 3).

An initial bile duct excision was made $1 \mathrm{~cm}$ proximal to the tumor and distally down to the upper border of the pancreas. Kocherization of the duodenum allowed exposure of the retroperitoneum and visualization of the neighboring structures. A lymph node at station $8 \mathrm{~A}$ was excised. Following bile duct 


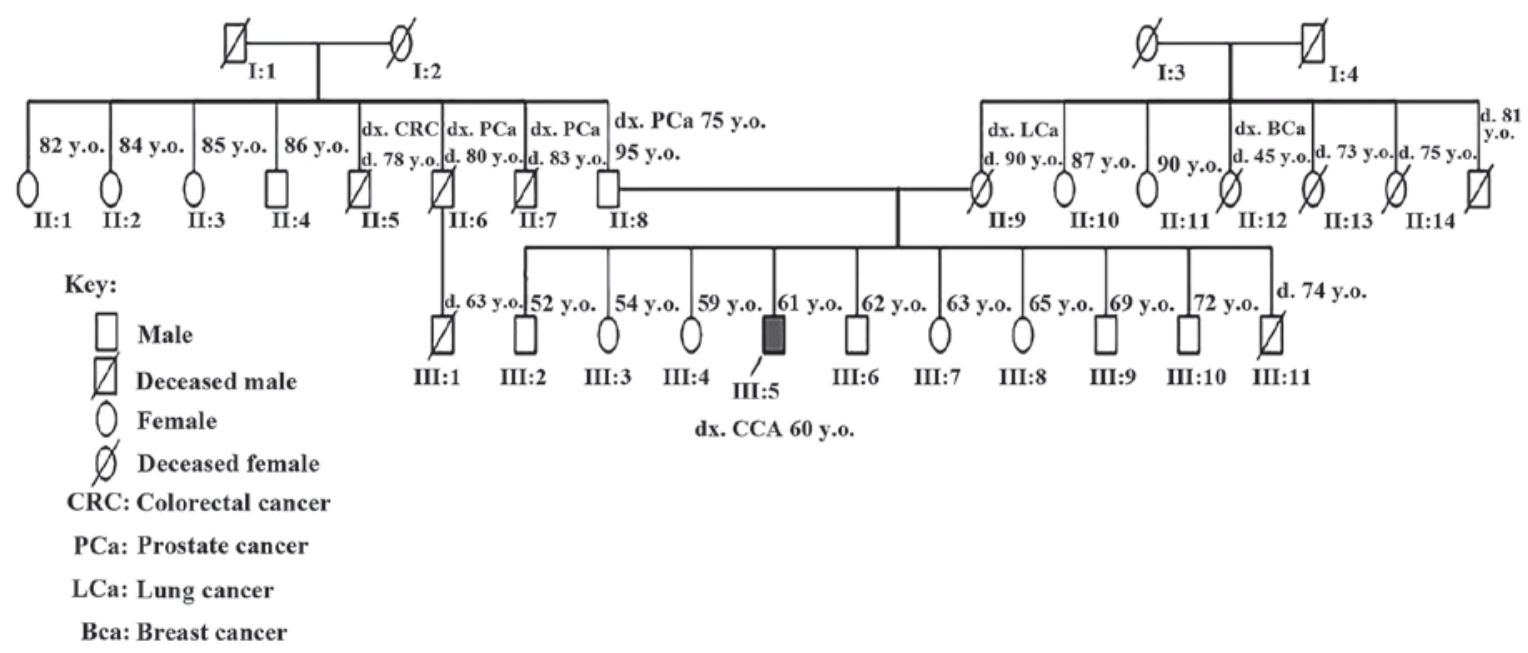

Figure 1. Pedigree analysis of the patient.

excision, imprint cytology demonstrated that both superior and inferior margins were invaded by the tumor. The proximal bile duct was re-excised to the hepatic ductal confluence, however, this margin was also positive. A pancreaticoduodenectomy (Whipple procedure) was performed to gain a clear distal margin but no further resection was done on the proximal bile duct, due to the lack of intra-operative imprint cytology at that time leaving us unable to perform a right vs. left hepatectomy, as we were unsure which hepatic duct was involved. The MRCP demonstrated it was free of tumor and macroscopically both ducts appeared normal.

Macroscopically, the cut surface of common bile duct revealed an ulcero-proliferative lesion $(3.0 \times 2.0 \times 1.5 \mathrm{~cm})$, $0.2 \mathrm{~cm}$ from the proximal bile duct margin and $1.0 \mathrm{~cm}$ from the distal bile duct margin. Histology revealed T2N1M0 moderately differentiated CCA with a positive proximal resection margin and metastatic deposits in station 8A lymph node along with peri-neural invasion (Fig. 4). Post-operatively, the patient had bile noted from the drains with resolution after two weeks. Six-months postoperative, the patient is receiving adjuvant chemotherapy (capecitabine) and has completed 30 cycles of external beam radiotherapy to the porta hepatis due to the positive proximal margin. At six months follow up, the patient showed small hepatic metastasis upon CT screening.

\section{Discussion}

In Trinidad and Tobago there were 65 reported CCA cases from $1995-2007$, accounting for $0.41 \%$ of all incident cancer cases (personal communication from the Trinidad and Tobago National Cancer Registry). There was a slight male predilection $(56.9 \%)$ and the overall average incident age was 60-69 years. The present case report, in addition to the majority of cases $(66.1 \%)$ in TT originate in the extrahepatic bile duct, with the remaining cases occurring in the biliary track NOS (13.8\%) followed by the Ampulla of Vater (0.2\%). Forty-six percent of cases were diagnosed at autopsy and the majority of the other cases were diagnosed by histology of the primary tumor. The majority of cases occurred in nationals of African (63.1\%), Indian (29.2\%) then Mixed (African-Indian) ancestry $(7.7 \%)$. This contrasts with data from the USA, where

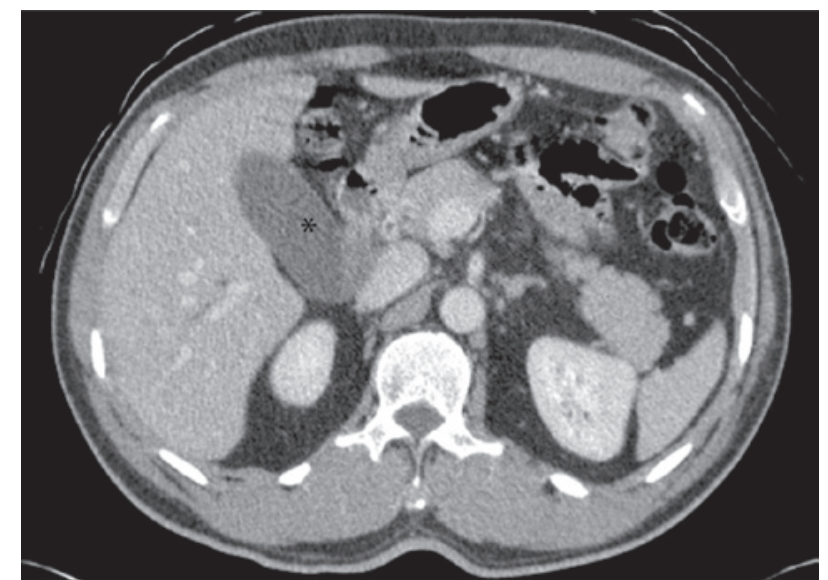

Figure 2. Computed tomography showing the dilated intra-hepatic ducts, gallbladder (indicated by ${ }^{*}$ ), cystic duct and common hepatic duct, just distal to the entrance of the cystic duct.

Hispanics and Asians have higher incident rates compared to African Americans (7).

The general risk factors for cholangiocarcinoma are primary sclerosing cholangitis (PSC), recurrent pyogenic cholangitis, hepatolithiasis, primary biliary cirrhosis, cholelithiasis, Asian liver flukes, biliary malformation (Caroli's disease, choledochal cysts), toxins (thorotrast, dioxin, polyvinyl chloride and heavy alcohol use), and viral infection (HIV, hepatitis B and hepatitis C and EBV) (10-14). There was no evidence that our patient was exposed to these risk factors. In fact, most CCA cases like the one presented in the current study arise de novo (12).

Clinical management of these cases is challenging and requires a multimodality approach. While surgical resection is an optimal treatment approach, many patients are not candidates as the disease is often diagnosed at an advanced stage given that diagnostic symptoms like night sweats, malaise, jaundice, abdominal pain and cachexia are not uniquely informative (15). Another compounding factor is the possibility of metastatic spread to the hepatic vasculature, regional lymph nodes, lung, bones (especially vertebrae), adrenal system and brain. 


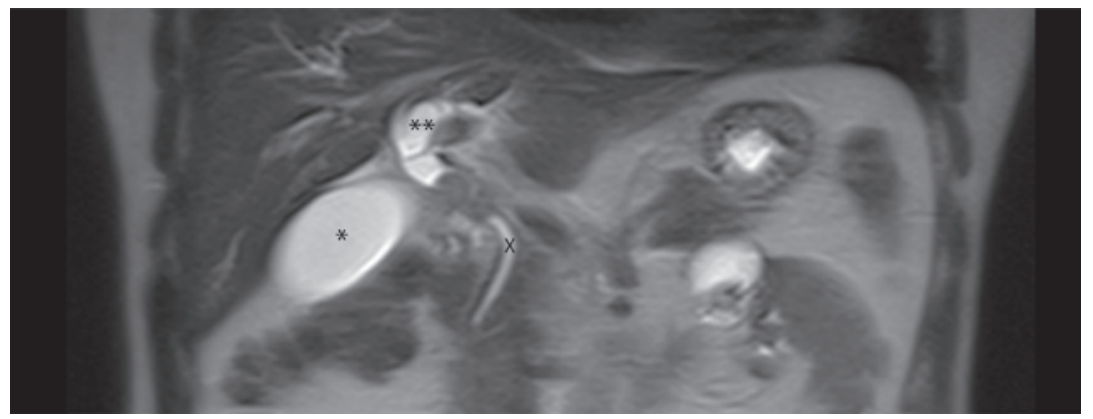

Figure 3. MRCP scan showing the mass in the proximal CBD. MRCP, magnetic resonance cholangiopancreatography. The normal distal bile duct (indicated by $\mathrm{X}$ ), gall bladder (indicated by*), and dilated proximal hepatic duct (indicated by**) are noted.

A
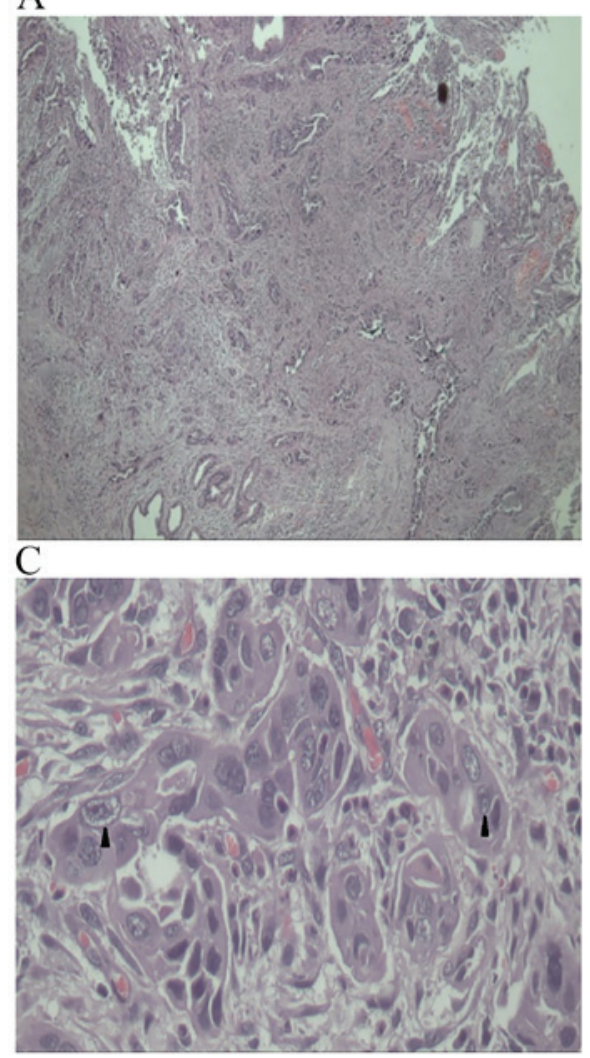

B

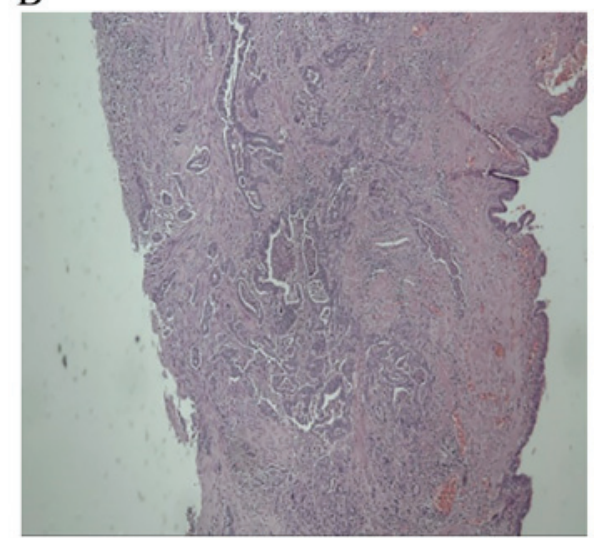

$\mathrm{D}$

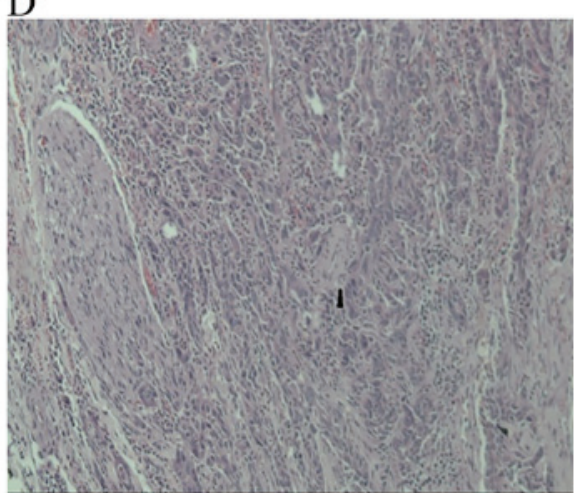

Figure 4. Moderately differentiated adenocarcinoma with involvement of proximal and distal surgical resected margins of the common bile duct. (A) Proximal bile duct margin. H\&E, staining. Magnification, x40. (B) Distal bile duct margin. H\&E staining. Magnification, x10. (C) Distal bile duct margin showing neoplastic cells at the margin (arrowhead). H\&E staining. Magnification, x100. (D) Characteristic perineural invasion (arrowhead). H\&E staining. Magnification, $\mathrm{x} 40 . \mathrm{H} \& \mathrm{E}$, hematoxylin and eosin.

According to the 8th edition of the Union for International Cancer Control-American Joint Committee on Cancer (UICC-AJCC) classification there are two divisions of extrahepatic cholangiocarcinoma-distal and perihilar. For distal extrahepatic CCA, tumor depth invasion, number of lymph node metastases, perineural, microscopic vascular invasion, $\mathrm{R} 0$ resection and pancreatic invasion are reported to be predictors of long term survival (16-23). A single positive bile duct resection margin is usually correlated with increased risk of recurrence and poor prognosis, as is a positive lymph node $(24,25)$. A recent study that examined 27 patients with distal bile duct cancer who underwent pancreatoduodenectomy with extended lymphadenectomy identified that factors for improved survival included up to two positive nodes, negative resection margins, and clinical administration of postoperative adjuvant chemotherapy (21).

Generally the prognosis for CCA is poor with 5-year survival of 5-10\%, and a median survival of 3-6 months if unresectable $(13,26)$. Post surgery survival time depends on a thorough resection with negative resection margins. It is well established that recurrences occur in $60-80 \%$ of patients within two years after the initial surgery (27). In the present case, given that the regional lymph nodes were positive our challenge was deciding how far to resect. We had to weigh the probability of local vs. distant recurrence and the morbidity and potential mortality of trying to gain a R0 proximal margin. 
It was ultimately decided that the probability of distant recurrence outweighed that of local recurrence.

Adjuvant therapy is often considered as part of the clinical management for post operative CCA where there are positive margins given the high rate of recurrence in these circumstances (28). Studies have reported survival benefits for chemoradiotherapy with incompletely resected tumors $(3,29)$. A recent study looking at chemoradiation with 5-fluorouracil (5-FU) and external beam irradiation reported improved survival for distal tumors particularly in patients with histologically positive resection $(30,31)$. It has been reported that gemcitabine-based approaches have better survival outcomes than 5-FU and should be considered as part of the clinical intervention (13). A recent report demonstrated that a low bilirubin level $<10 \mathrm{mg} / \mathrm{dl}$ and chemotherapy administration are independent predictors associated with better survival (32).

Despite the genetic heterogeneity of CCA, perturbation of the RAS-MAPK pathway has been increasingly viewed as a potential signature genetic aberration in CCA (33-37). In Trinidad and Tobago, CCA provides an opportunity to integrate epidemiological data, genomics, and novel clinical approaches to better screen and treat CCA cases (38). One such schema integrates diagnostic tests, and identification of targetable cancer driver pathways leading to personalized targeted therapy $(33,34)$.

In conclusion, the present case demonstrates clearly that intra-operative assessment of margins in resection of CCA are paramount. Aggressive surgical resection followed by adjuvant therapy shows a definitive survival advantage. This case presented challenges given the difficulties to obtain a correct preoperative diagnosis, and to achieve R0 margins. Further studies are required to identify modalities to better diagnose and clinically intervene in these cases.

\section{Acknowledgements}

The authors of the present study appreciate the contributions of the Department of Pathology, Eric Williams Medical Sciences Complex, Trinidad and the assistance of Krishna Vyas, Washington University, St. Louis, USA with figure preparation. WAW was supported by Washington University School of Medicine-St. Louis (grant no., GSAS/CGFP Fund 94028C).

\section{References}

1. Steiner PE: Carcinoma of the liver in the United States. Acta Unio Int Contra Cancrum 13: 628-645, 1957.

2. Esposito I and Schirmacher P: Pathological aspects of cholangiocarcinoma. HPB (Oxford) 10: 83-86, 2008.

3. Nakeeb A, Pitt HA, Sohn TA, Coleman J, Abrams RA, Piantadosi S, Hruban RH, Lillemoe KD, Yeo CJ and Cameron JL: Cholangiocarcinoma. A spectrum of intrahepatic, perihilar, and distal tumors. Ann Surg 224: 463-475, 1996.

4. Klöppel G, Adsay V, Konukiewitz B, Kleeff J, Schlitter AM and Esposito I: Precancerous lesions of the biliary tree. Best Pract Res Clin Gastroenterol 27: 285-297, 2013.

5. Nuzzo G, Giuliante F, Ardito F, Giovannini I, Aldrighetti L, Belli G, Bresadola F, Calise F, Dalla Valle R, D'Amico DF, et al: Improvement in perioperative and long-term outcome after surgical treatment of hilar cholangiocarcinoma: Results of an Italian multicenter analysis of 440 patients. Arch Surg 147: 26-34, 2012

6. Yamamoto M and Ariizumi S: Surgical outcomes of intrahepatic cholangiocarcinoma. Surg Today 41: 896-902, 2011.
7. Rizvi S and Gores GJ: Pathogenesis, diagnosis, and management of cholangiocarcinoma. Gastroenterology 145: 1215-1229, 2013

8. Khan SA, Davidson BR, Goldin RD, Heaton N, Karani J, Pereira SP, Rosenberg WM, Tait P, Taylor-Robinson SD, Thillainayagam AV, et al: Guidelines for the diagnosis and treatment of cholangiocarcinoma: An update. Gut 61: 1657-1669, 2012.

9. Parkin DM, Ohshima H, Srivatanakul P and Vatanasapt V: Cholangiocarcinoma: Epidemiology, mechanisms of carcinogenesis and prevention. Cancer Epidemiol Biomarkers Prev 2: 537-544, 1993.

10. Chung YE, Kim MJ, Park YN, Choi JY, Pyo JY, Kim YC, Cho HJ, Kim KA and Choi SY: Varying appearances of cholangiocarcinoma: Radiologic-pathologic correlation. Radiographics 29: 683-700, 2009.

11. Welzel TM, Graubard BI, El-Serag HB, Shaib YH, Hsing AW, Davila JA and McGlynn KA: Risk factors for intrahepatic and extrahepatic cholangiocarcinoma in the United States: A population-based case-control study. Clin Gastroenterol Hepatol 5: 1221-1228, 2007

12. Lazaridis KN and Gores GJ: Cholangiocarcinoma. Gastroenterology 128: 1655-1667, 2005.

13. Reddy SB and Patel T: Current approaches to the diagnosis and treatment of cholangiocarcinoma. Curr Gastroenterol Rep 8: 30-37, 2006.

14. Shaib YH, El-Serag HB, Davila JA, Morgan R and McGlynn KA: Risk factors of intrahepatic cholangiocarcinoma in the United States: A case-control study. Gastroenterology 128: 620-626, 2005.

15. El RassiZE, Partensky C, Scoazec JY, Henry L,Lombard-Bohas C and Maddern G: Peripheral cholangiocarcinoma: Presentation, diagnosis, pathology and management. Eur J Surg Oncol 25: 375-380, 1999.

16. Ito K, Ito H, Allen PJ, Gonen M, Klimstra D, D'Angelica MI, Fong Y, DeMatteo RP, Brennan MF, Blumgart LH and Jarnagin WR: Adequate lymph node assessment for extrahepatic bile duct adenocarcinoma. Ann Surg 251: 675-681, 2010.

17. Hong SM, Pawlik TM, Cho H, Aggarwal B, Goggins M, Hruban RH and Anders RA: Depth of tumor invasion better predicts prognosis than the current American joint committee on cancer $\mathrm{T}$ classification for distal bile duct carcinoma. Surgery 146: 250-257, 2009.

18. Yoshida T, Matsumoto T, Sasaki A, Morii Y, Shibata K, Ishio $\mathrm{T}$ and Kitano $\mathrm{S}$ : Lymphatic spread differs according to tumor location in extrahepatic bile duct cancer. Hepatogastroenterology 50: 17-20, 2003.

19. Ebata T, Nagino M, Nishio H, Igami T, Yokoyama Y and Nimura Y: Pancreatic and duodenal invasion in distal bile duct cancer: Paradox in the tumor classification of the American joint committee on cancer. World J Surg 31: 2008-2015,2007.

20. Murakami Y, Uemura K, Hayashidani Y, Sudo T, Ohge H and Sueda T: Pancreatoduodenectomy for distal cholangiocarcinoma: Prognostic impact of lymph node metastasis. World J Surg 31: 337-344, 2007.

21. Yoshida T, Matsumoto T, Sasaki A, Morii Y, Aramaki M and Kitano S: Prognostic factors after pancreatoduodenectomy with extended lymphadenectomy for distal bile duct cancer. Arch Surg 137: 69-73, 2002.

22. Murakami Y, Uemura K, Hayashidani Y, Sudo T, Hashimoto Y, Ohge $\mathrm{H}$ and Sueda T: Prognostic significance of lymph node metastasis and surgical margin status for distal cholangiocarcinoma. J Surg Oncol 95: 207-212, 2007.

23. Woo SM, Ryu JK, Lee SH, Yoo JW, Park JK, Kim YT, Jang JY, Kim SW, Kang GH and Yoon YB: Recurrence and prognostic factors of ampullary carcinoma after radical resection: Comparison with distal extrahepatic cholangiocarcinoma. Ann Surg Oncol 14: 3195-3201, 2007.

24. Sasaki R, Takeda Y, Funato O, Nitta H, Kawamura H, Uesugi N, Sugai T, Wakabayashi G and Ohkohchi N: Significance of ductal margin status in patients undergoing surgical resection for extrahepatic cholangiocarcinoma. World J Surg 31: 1788-1796, 2007.

25. Kitagawa Y, Nagino M, Kamiya J, Uesaka K, Sano T, Yamamoto H, Hayakawa $\mathrm{N}$ and Nimura Y: Lymph node metastasis from hilar cholangiocarcinoma: Audit of 110 patients who underwent regional and paraaortic node dissection. Ann Surg 233: 385-392, 2001.

26. Jarnagin WR, Fong Y, DeMatteo RP, Gonen M, Burke EC, Bodniewicz BS J, Youssef BA M, Klimstra D and Blumgart LH: Staging, resectability, and outcome in 225 patients with hilar cholangiocarcinoma. Ann Surg 234: 507-519, 2001. 
27. Soares KC, Kamel I, Cosgrove DP, Herman JM and Pawlik TM: Hilar cholangiocarcinoma: Diagnosis, treatment options, and management. Hepatobiliary Surg Nutr 3: 18-34, 2014.

28. Brandi G, Venturi M, Pantaleo MA and Ercolani G; GICO Cholangiocarcinoma: Current opinion on clinical practice diagnostic and therapeutic algorithms: A review of the literature and a long-standing experience of a referral center. Dig Liver Dis 48 231-241, 2016.

29. Serafini FM, Sachs D, Bloomston M, Carey LC, Karl RC, Murr MM and Rosemurgy AS: Location, not staging, of cholangiocarcinoma determines the role for adjuvant chemoradiation therapy. Am Surg 67: 839-844, 2001.

30. Anderson CD, Pinson CW, Berlin J and Chari RS: Diagnosis and treatment of cholangiocarcinoma. Oncologist 9: 43-57, 2004.

31. Pitt HA, Nakeeb A, Abrams RA, Coleman J, Piantadosi S, Yeo CJ, Lillemore KD and Cameron JL: Perihilar cholangiocarcinoma. Postoperative radiotherapy does not improve survival. Ann Surg 221: 788-798, 1995.

32. Farhat MH, Shamseddine AI, Tawil AN, Berjawi G, Sidani C, Shamseddeen W and Barada KA: Prognostic factors in patients with advanced cholangiocarcinoma: Role of surgery, chemotherapy and body mass index. World J Gastroenterol 14: 3224-3230, 2008.
33. Razumilava $\mathrm{N}$ and Gores GJ: Cholangiocarcinoma. Lancet 383 : 2168-2179, 2014.

34. Geynisman DM and Catenacci DV: Toward personalized treatment of advanced biliary tract cancers. Discov Med 14: 41-57, 2012.

35. Han W and Lo HW: Landscape of EGFR signaling network in human cancers: Biology and therapeutic response in relation to receptor subcellular locations. Cancer Lett 318: 124-134, 2012.

36. Andersen JB, Spee B, Blechacz BR, Avital I, Komuta M, Barbour A, Conner EA, Gillen MC, Roskams T, Roberts LR, et al: Genomic and genetic characterization of cholangiocarcinoma identifies therapeutic targets for tyrosine kinase inhibitors. Gastroenterology 142: 1021-1031.e15, 2012.

37. Brandi G, Farioli A, Astolfi A, Biasco G and Tavolari S: Genetic heterogeneity in cholangiocarcinoma: A major challenge for targeted therapies. Oncotarget 6: 14744-14753, 2015.

38. Roach A, Warner WA and Llanos AA: Building capacity for human genetics and genomics research in Trinidad and Tobago. Rev Panam Salud Publica 38: 425-430, 2015. 